\title{
Analysis of the Relationship Between Unemployment and Crime Rate in China
}

\author{
Xiaoye Wang ${ }^{1, *}$, Shixin $\mathrm{Hu}^{2}$ \\ ${ }^{1}$ University California of SantaBarbara, Santa Barbara, US, 93106 \\ ${ }^{2}$ Yinhe SOHO, Dongcheng District, Beijing, China, 100005 \\ *Corresponding author. Email: xiaoye@umail.ucsb.edu
}

\begin{abstract}
With the tremendous changing of social economic activity, crime rate has an increasing trend. Urbernization rate, divorce rate, GDP, education, and unemployment rate all have certain correlation to crime rate and This paper focused on one concerned question in economics of crime, which is the relationship between unemployment rate and crime rate. There are bunch of factors that could influenced crime rate, such as the development of economy, gap of income, urbanization, education, labor markets; unemployment rate is one of the standards that could measure economy, and it has certain relationship with crime rate. Crime rate is treated as dependent variable, and unemployment rate as independent variable. Also, income inequality, education level, development of economy, population density, budget of government justice system, population mobility, and consumption of alcohol are added as independent variables. City-level panel data and Fixed Effect and Random Effect Model are used to do the empirical analysis toward unemployment and crime rate. According to the regression results, an obvious significant positive correlation between unemployment rate and crime rate. Under Fixed Effect Model, when there is one percent increasing of crime unemployment rate, crime rate will move $0.72 \%$ up, and $0.67 \%$ for Random Effect Model. Meanwhile, we find that level of economic development, population mobility, consumption of alcohol, income inequality all have significant positive correlation with crime rate. However, education level, population density, and budget of government justice system do have significant relationship with crime rate.
\end{abstract}

Keywords: crime rate; unemployment rate; regression analysis

\section{INTRODUCTION}

Crime has accompanied human since there is existence of society, and it likes financial crises, closely related to humans' life, never extinct, but its occurrence has its own periods of peak and undervaluation frequency. For example, in China, since 1978 the reform and opening up period begun, although the economic in China has grew up tremendously, the crime rate did not have an outstanding decent tendency. To be specific, crimes frequency and extent of harm has expanded; with the development of economy, cases of economic crimes has increased; migrant population has become the major criminal group. With such ample phenomenon, scholars have investigated more into reasons of what cause people do crime, and take researches in multiple areas. From the past, in prosperous era, people lived a better life, and crime rate is low; while in war time, crime behaviors happened rampantly. In a word, when economy is prosperous, crime rate is low, and when it in recession, crime rate will increase.

This paper analyzes the cases of crimes in China during 1981-2009, in these twenty years, cases of crime in China have wavelike rise. In 1981-1987, number of cases decreases slightly, but in the next four years, number of cases has a huge rising. In next eight years until 1999, all number of cases has been stable, and does not too much change; from 2000 to 2009 , the number of cases has a apparent leap. We also gather the data of unemployment during this period, and found that from 1981-1986, the unemployment rate has fallen quickly down to $1.6 \%$, and increased tardily in the next ten years, but during 2000-2003, there is a huge upward of unemployment rate, up to $4.3 \%$; while from 2004-2007 the unemployment rate decreased slowly, but still stabled at 4\%, and upward a little bit during 2008-2009. In a conclusion, from 2000, China's unemployment rate has been at a high level. Aiming at the situation of 
unemployment and crime, we studied whether these two have correlation or even positive relationship.

By doing this analysis, and test related hypothesis, our group could investigate whether governments could lower crime rate by making management and control unemployment rate. Moreover, by analyzing the relationship between unemployment and crime rate, our group realize that crime is not a barely a personal, subjective decision making, but a derivative issue of social problem. If such view could be taking more seriously, then this may not only impact crime rate, but also a promotion to social climate.

\section{THEORETICAL BASIS}

Crime as a legislative affair, has been strongly grounded in pledge, ethical determination and credence. Its attractiveness ensues from the viewpoint in believing in the principle that all people are equal and deserve equal rights and opportunities [1]. Ne plus ultra of an international society and orthodox civility provided the virtual feathers that promoted it to move up upon the orbit of the system of politics or principles based on practical rather than moral or ideological considerations. By evaluating its feasible political repercussions, and contrasting it to veritable and feasible political unorthodox, the proposition will be deprived of the quality of seeming probable, particularly in the globe where constructive fabrications are not alleged to be indulged. The interrogation in which the author endures irreligious is that if the natural rate supposition is accurate and if kinds of configuration of the phenomenon in which the value of a physical property lags behind changes in the effect causing it, as for instance when magnetic induction lags behind the magnetizing force generates fiscal disturbances to have permanent reverberations on unemployment [2].

The criminal evidence complication is issue of a variety of coinciding tendency in contemporary periods. The strategy fortified an appreciable growth in citizen comes upon with statute implementation, which excessively collided with clique. Dossiers of the engagements have grown simply attainable deserved by the wide instruction allocating project constructed realizable according to the information superhighway and promoted by jurisprudences [3]. The bars act as a substitute for a continuous appearance of disciplining for humans with malefactor reports. We survey the aspects that furnishing to the illegitimates evidence obstacle, the guarantee ramification, and the particular employment problems with criminal datas. Qualification investigations legislated under the aegis of jurisprudence have grown since 2001, under the authority of laws, state legislatures have given the seal of approval to over thousand having need of qualification inspections by law administration bureaus [4]. Most of the enactments need record probes for permitted postures or employment in permitted provisions.

The imprecisions from scarcities in district's supervision criminal records, on which the agency depends on improving its structured set of data. Sub rosa milieu probe corporates frequently share imprecise details. As claimed by pundits, records put forward through mercantile corporates often comprise data about incorrect people, present secured data, exclude the current tendency of probes, make record in a deluding way, or describe detail insulated from declaration via clients and privacy laws [5].

Notwithstanding the fact that experimentation has emphasized that the effect of a penitentiary previous conduct on employment chances, encompassing proletarian competitor contingency percentages and disadvantaged remunerations throughout period, criminal history of interruptions and transgressions canister present with important obstacles to employment. A subsidiary criminal history tin can impede a licensed competitor from being interrogated [6]. If an employer who demonstrates an inclination to employ candidates with criminal history peradventure not indeed do so. A subsidiary criminal data conceivably equally be the defense of a commission's contradiction or an official cancellation of a decree of an authorization. Likewise, while record probe corporates are not assumed to announce most criminal record details. Illegitimate records accompany lots of people identical to a scintilla [7]. Delinquent data denounce society and produce indemnification outcomes that restrict their chances [8]. When a criminal history does not be a measure of a concluded impediment to employment, it can influence employment right set of circumstances.

\section{METHODOLOGY}

Empirical analysis will be done after having analyzed the relationship between unemployment rate and crime rate theoretically.

\subsection{Data Description}

This paper uses data from provincial-level panel data to exam the relationship between crime rate and unemployment rate. Since the paper is to verify whether there is connection between crime rate and unemployment rate, and to split out effect unemployment bring, deliberating those factors that will changed with periods of regional business cycles and do impact to crime rate is a crucial step.

By Philip cook and Gary Zarkin's research, they suggest four categories of factors that may link crime rate and business cycles: (1) achieve legitimate working opportunities, (2) the chance to do crime, (3) 
consumption that may promote crime behaviors (drugs, alcohol, guns, etc.), (4) justice systems' response to criminal behaviors. The (2), (3), (4) factors will variate with economic period. During economic recession, due to the decreasing of income and consumption of potential victims, the opportunity of crime behaviors decreased relatively [9]. Despite above factor, the other factors, such as drugs, alcohol, and justice systems' efficiency and effort are all variate with different periods. Thus, their impacts will be tempered when there is a economic recession. In Steven Raphael and Rudolf Winter-Ebmer's article [10], they conclude a complete model:

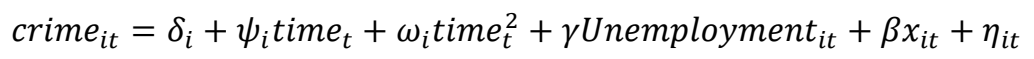

While $i$ and $t$ represent city and year separately, crime $_{i t}$ is Logarithm of crime rate in per 10000 inhabitants. Unemployment $t_{i t}$ represents rate of unemployment. $x_{i t}$ is a set of control variables. $\delta_{i}$ is individual fixed effect. time $_{t}$ and time $t_{t}^{2}$ is linear and quadratic time trend. $\psi_{i}$ is the coefficient of linear time trend, $\omega_{i}$ is the coefficient of quadratic time trend. $\gamma$ is the semi elasticity of the crime rate with respect to the unemployment rate, $\beta$ is the vector of parameters for the control variables in $x_{i t}$, and $\eta_{i t}$ is the residual.

First, in order to measure the periodic changing of products consumption that could trigger crime, they add alcohol consumption, but in China, drugs and guns are relatively a weak impactor, thus they add population density, because with the increasing of density, it also promotes the chance of doing crime, then influenced crime rate. Also, they have added the difference of poverty proportion between city and rural areas, since huge gap of wealth may let poverty people get worse, and force them to do crime, on the other hand, high income of rich people may provide potential opportunities for criminals. What's more, the justice system budget also will be influenced crime rate, when budget is higher, which means society's justice system is paying more attention, and that will threat criminals thus decrease crime rate. According to Philip and Gary theories, during economic recession, since potential victim's income become less, consumption decrease, and spend more time to protect their own properties, hence criminals' chance has decreased. Besides, they have added education, on one hand, popularize education, especially elementary education could improve national quality, on the other hand, higher education could promote high technology crimes, so education is related to crime rate. Lastly, they add population mobility, because in China, average income of migrant population is not adequate as well as education, and their management is chaos, thus they are more likely to do crime. In this paper, we use number of people in every one hundred thousand who have college degree as variable of education.
Since observing all factors that could influenced crime and economic period changing is impossible, our control variables are incomplete. To further adjust unobserved variables, and reduce resulting measurement variation, we will fully exploit our panel-data characteristics. First, this paper adds individual fixed effects model to eliminate variables that adjusted with provenance but not time periods. Furthermore, this research also adds time fixed effects to canceled those variables that will be same for all individual provenances but will changed with time. Finally, we add linear and quadratic time trend to eliminate variation in individual provenance that will changed with time and then influenced crime rate.

Lastly, this paper adds 2001's “attack 1" and 2008's "attack 2" these two virtual variables, because for twenty-one centuries, China has appeared the fifth crime peak, thus we have added "attack 1", and during 2008, because of the Olympic game in Beijing, there is another "attack 2".

\subsection{Data selection and meaning of variables}

This paper uses twenty provincial capitals or municipalities statistic data from 2000-2009 as our quantitative analysis resource, including, Beijing, Tianjin, Shanghai, Chongqing, Jinan, Guangzhou, Hangzhou, Nanjing, twenty cities, two hundred observe values totally. Crime rate is from every city's annual "Report on the Work of the Procuratorate", and all other data are from "City Statistical Yearbook". Since some annual data are missing, common make up method for missing values are applied, if data between two years is missing, average value of two years data is used for make-up value.

Unemployment rate: since China does not have specific unemployment rate statistic, cities and towns unemployment rate data is used for substitution. This paper selects twenty highly-developed cities data, which have higher education level, thus applying these cities data for substitute variable has less measurement variation. 
Table 1. Variables in the model

\begin{tabular}{|c|c|}
\hline Variables & Definition of variables \\
\hline \multicolumn{2}{|r|}{ Explained variable } \\
\hline Crime rate & Logarithm of crime rate in per 10000 inhabitants \\
\hline Dependent variable & Unemployment rate in China (unit: \%) \\
\hline \multicolumn{2}{|r|}{ Independent variable } \\
\hline Avgdp & Average GDP (unit: yuan) \\
\hline Alcohol Consumption & Average alcohol consumption per year (unit: liter/person) \\
\hline Popdensity & Population density (unit: person/ square kilometer) \\
\hline Police & The budget proportion of justice system in whole fiscal expenditure (unit: \%) \\
\hline Inequality & The proportion of per capita disposable income between city and rural area \\
\hline FP & The proportion of Immigrant population to permanent resident population \\
\hline Education & The population of people have college degree or higher in per 10000 inhabitants \\
\hline Attack 1 & 2001 virtual "attack" variable \\
\hline Attack 2 & 2008 virtual "attack" variable \\
\hline Time 1 & Linear time trend \\
\hline Time 2 & Quadratic time trend \\
\hline
\end{tabular}

\subsection{Test Results}

Random effect and fixed effect regression analysis toward crime rate under no time trend have been done. The result (Table 2) shows that, no matter under fixed effect or random effect model, unemployment rate and crime rate are significantly positive correlated. Crime rate and unemployment rate are both significantly positive correlated under $95 \%$ fixed effect model significance level, and 90\% random effect model significance level. Increasing of unemployment rate will cause crime rate increase as well, in fixed effect model, an increasing of $1 \%$ of unemployment will cause crime rate increase $0.72 \%$. Under random effect model, an increasing of $1 \%$ of unemployment will cause crime rate increase $0.67 \%$. In other influenced factors, average GDP has significant positive correlation with crime rate. Higher average GDP has surprisingly increased crime rate, and that may because with development of economy, improvement of average GDP amplifies the income gap, thus increased crime rate.

Table 2. Regression results of fixed effect and random effect model on crime rate

\begin{tabular}{|l|l|l|}
\hline Variable & Fixed effect model & Random effect model \\
\hline Unemployment & $0.72^{* *}$ & $0.67^{* *}$ \\
\hline Avgdp & $0.04^{* *}$ & $0.03^{* *}$ \\
\hline Alcohol consumption & $0.17^{* *}$ & $0.198^{* * *}$ \\
\hline Popdensity & 0.04 & 0.02 \\
\hline Police & $1.61^{*}$ & 1.55 \\
\hline Inequality & $0.091^{* * *}$ & $0.082^{* * *}$ \\
\hline FP & $0.77^{* *}$ & $0.82^{*}$ \\
\hline Education & -0.03 & -0.12 \\
\hline Attack1 & $0.163^{* * *}$ & $0.73^{* * *}$ \\
\hline Attack2 & $0.282^{* *}$ & $0.249^{*}$ \\
\hline
\end{tabular}

Consumption of alcohol also has positive correlation with unemployment rate; under fixed effect model and random effect model, every increasing of $1 \%$ of consumption of alcohol will increased crime rate $0.17 \%$ and $0.19 \%$; while population density does not have correlation with unemployment rate. However, under fixed effect model, budget of government justice system has significant positive correlation, which means with higher budget, crime rate will increase, that may because the enhancement of budget is due to higher crime rate, which budget of government justice system has casual relationship with crime rate. Regression result also indicates that unfair income enhances crime rate as well, every increasing of $1 \%$ unfair income will cause crime rate increase $0.091 \%$ and $0.082 \%$ under fixed effect and random effect model. Population mobility also has positive correlation with crime rate, under $95 \%$ fixed effect model significance level. Every increasing of $1 \%$ of population mobility, crime rate will increase $0.77 \%$. Under $90 \%$ random effect model 
significance level, population mobility also has positive correlation with crime rate, which every increasing of $1 \%$ of mobility will increase crime rate $0.82 \%$.
However, two "attack" have increase crime rate, because "attack" may cause more criminal to be arrested.

Table 3. Regression result of crime rate after adding linear and quadratic time trend

\begin{tabular}{|l|c|c|c|c|c|c|}
\hline \multicolumn{1}{|c|}{ Variables } & \multicolumn{3}{c|}{ Fixed effect model } & \multicolumn{3}{c|}{ Random effect model } \\
\hline & no time trend & linear time trend & quadratic time trend & no time trend & linear time trend & quadratic time trend \\
\hline Unemployment & $0.72^{* *}$ & $0.70^{* * *}$ & $0.67^{* *}$ & $0.67^{* *}$ & $0.64^{*}$ & $0.60^{*}$ \\
\hline Avgdp & $0.04^{* *}$ & $0.04^{* *}$ & $0.03^{* *}$ & $0.03^{* *}$ & $0.06^{* * *}$ & $0.08^{* * *}$ \\
\hline Alcohol consumption & $0.17^{* *}$ & $0.18^{* *}$ & $0.06^{* *}$ & $0.198^{* * *}$ & $0.187^{* * *}$ & $0.177^{* * *}$ \\
\hline Popdensity & 0.04 & 0.03 & $0.03^{*}$ & 0.02 & -0.04 & 0.03 \\
\hline Police & $1.61^{*}$ & 1.44 & 1.32 & 1.55 & 1.25 & 1.62 \\
\hline Inequality & $0.091^{* * *}$ & $0.088^{* * *}$ & $0.062^{* * *}$ & $0.082^{* * *}$ & $0.076^{* * *}$ & $0.072^{* * *}$ \\
\hline FP & $0.77^{* *}$ & $0.78^{*}$ & $0.80^{* *}$ & $0.82^{*}$ & $0.77^{*}$ & $0.69^{*}$ \\
\hline Education & -0.03 & 0.05 & -0.03 & -0.12 & -0.08 & -0.14 \\
\hline Attack1 & $0.163^{* * *}$ & $0.157^{* * *}$ & $0.147^{* * *}$ & $0.73^{* * *}$ & $0.71^{* * *}$ & $0.67^{* * *}$ \\
\hline Attack2 & $0.282^{* *}$ & $0.261^{* *}$ & $0.233^{* *}$ & $0.249^{*}$ & $0.198^{* *}$ & $0.101^{* *}$ \\
\hline
\end{tabular}

As Table 3 showed, this paper also adds linear time trend and quadratic time trend to do regression analysis toward crime rate under fixed effect and random effect model. The result shows that under fixed effect model, unemployment rate and crime rate still have significance positive correlation under $95 \%$ significance level, but the value is getting smaller, from 0.72 to 0.70 , and down to 0.67 . Under random effect model, unemployment and crime rate still remain positive correlation under 90 percent significance level, but the value is becoming smaller either, from 0.67 to 0.64 and to 0.60 . While in other variables, under fixed effect model, with linear and quadratic time trend, budget of justice system and crime rate's significance relationship has been weakened, to non-significance; while population density and crime rate's non-significance positive correlation has turned to significance under adding of linear and quadratic time trend, when there is one percent increasing of population density, crime rate increase $0.03 \%$.

\section{CONCLUSION}

Whilst some evidences are for consequential crimes, the majority are for detentions or reasonably transgressions. In an epoch of enhanced guarantee considerations, accessible records, and heightened criminal record probes, these documentations take actions as a considerable fence to profitable employment and alternative chances. Political scientist pronounces humans with criminal history as individual with a detrimental occupation credence. In riposte to the complication, attorneys have sent into orbit uncovering strategies to support society grasp benign of legitimate evidence opening treatments. We surveyed an erratic exemplification of competitors in such initiatives, evaluate the effect of the criminal record glade mediation on employment results. Operating approaches to manage for option prejudice and the repercussions of conversions in the financial resources in our feature, substantiation is constructed that the data glade mediation amplified competitors' employment rates and norm salaries, and people strived for evidence glade mediation subsequent to an era of conquered salaries. Alternative investigation requires to be finished to perceive the permanence of the affirmative outcome and its sequels in divergent labor markets, in spite of that the discoveries propose that the data glade mediation produces a significant contrast in employment results for people with criminal history. The discoveries propose the significance of forward involvement to escalate employment chances for society with criminal data.

\section{AUTHORS' CONTRIBUTIONS}

This paper is completed together by Xiaoye Wang and Shixin $\mathrm{Hu}$. Xiaoye is responsible for the abstract, introduction, methodology part, and Shixin $\mathrm{Hu}$ is responsible for the theoretical basis and conclusion part.

\section{ACKNOWLEDGMENTS}

I would like to express my gratitude to my primary supervisor, Alisa Wang, who guided me throughout this project. I would also like to thank my friends and family who supported me and offered deep insight into the study.

\section{REFERENCES}

[1] Wilde, Louis L. Criminal Choice, Nonmonetary Sanctions, and Marginal Deterrence: A Normative Analysis. International Review of Law and Economics, 1992.

[2] Wilson, James Q., and Richard J. Herrnstein. Crime and Human Nature. New York: Simon \& Schuster, 1985. 
[3] Witte, Ann Dryden. Estimating the Economic Model of Crime with Individual Data. Quarterly Journal of Economics, 1980.

[4] Klerman, Daniel. Settlement and the Decline of Private Prosecution in Thirteenth-Century England. Law and History Review, 2001.

[5] Lab, Steven P., John T. Whitehead. An Analysis of Juvenile Correctional Treatment. Crime and Delinquency, 1988.

[6] LaFave, Wayne R. Criminal Law. St. Paul, Minn.: West Group, 2000.

[7] Levitt, Steven D. The Effect of Prison Population Size on Crime Rates: Evidence from Prison Overcrowding Litigation. Quarterly Journal of Economics, 1996.

[8] Hoffman, Jan. Crime and Punishment: Shame Gains Popularity. New York Times, 1997.

[9] Cook PhilipJ, Zarkin Gary A. Age, crime and the business cycle. Journal of Legal Studies 14, 1985, 695-698.

[10] Steven Raphael and Rudolf Winter - Ebmer. Identifying the Effect of Unemployment on Crime. The Journal of Law \& Economics, Vol. 44, No. 1, April 2001, pp. 259-283. 